\title{
Mechanism of Transesterification and Cyclization of Epoxy-Polycarbonate Blends Catalyzed by Quarternary Ammonium Salt
}

\author{
MING-SHIU LI, ${ }^{1}$ CHEN-CHI M. MA ${ }^{1, \star}$ MING-SHIU LU, ${ }^{2}$ MIAW-LING LIN, ${ }^{2}$ and FENG-CHIH CHANG ${ }^{2}$ \\ 'Institute of Chemical Engineering, National Tsing Hua University, Hsinchu 30043, Taiwan, Republic of China, \\ ${ }^{2}$ Institute of Applied Chemistry, National Chiao Tung University, Hsinchu 30043, Taiwan, Republic of China
}

\begin{abstract}
SYNOPSIS
The reaction of oxirane with carbonate using quarternary ammonium salts as catalyst has been studied. Curing is caused by the transesterification reaction of the oxirane cycle with the carbonate group that proceeds by an "insertion" mechanism in the stoichiometric system. The ratio of the reactants is two oxirane groups to one carbonate group. In the nonstoichiometric system, the epoxide content is more than the stoichiometric quantity required. A cyclization reaction is followed by the transesterification reaction. To identify the finished products, a model reaction was proposed using diphenyl carbonate and phenyl glycidyl ether which results in the formation of 4-phenoxymethyl1,3-dioxolane-2-one (PMD). The mechanism of forming the cyclic structure is assumed to proceed through the chain scission of the network in which the molecular chain crosslinked with carbonate group by a transesterification reaction. (c) 1996 John Wiley \& Sons, Inc.
\end{abstract}

Keywords: epoxy $\bullet$ blend $\bullet$ polycarbonate $\bullet$ transesterification $\bullet$ cyclization

\section{INTRODUCTION}

It has been well known that oxiranes can react with various active esters in the presence of quarternary ammonium salts. Nishikubo et al. ${ }^{1}$ identified the finished products from the reaction between oxirane and ester, and confirmed that an insertion reaction of epoxy compounds with ester linkage of poly [4-(4-nitrobenzoyloxy)styrene] occurred. The rate of the addition reaction of epoxide group with an activated ester using quarternary ammonium salts as a catalyst is proportional to the third-order reaction kinetics involving the epoxide, ester, and catalyst concentrations. The mechanism of the addition reaction is assumed to proceed by a transition state that is composed by epoxide, ester, and quarternary ammonium salts. ${ }^{2}$ A polyfunctional active ester was employed as a

* To whom all correspondence should be addressed. Journal of Polymer Science: Part A: Polymer Chemistry, Vol. 34, 3303-3312 (1996) (C) 1996 John Wiley \& Sons, Inc.
CCC 0887-624X/96/163303-10 new curing agent for epoxy resins and the relation between the degree of conversion and catalytic activity was discussed by Nishikubo et al. ${ }^{3-5}$ Komarova et $a .^{6}{ }^{6}$ studied the interaction of epoxy oligomer with polycarbonate and discovered that the solubility of the mixture decreased while the thermomechanical properties increased after thermal treatment. This phenomenon was interpreted as the formation of a crosslinked structure. Bell et al. ${ }^{7}$ also investigated PC-epoxy blends cured by a quarternary ammonium salt and reported that the crosslink density of the resultant three-dimensional network can be controlled by adjusting the epoxy/carbonate ratio. However, most earlier studies were carried out based on a $1: 1$ stoichiometric system of the epoxide polycarbonate copolymer networks, and very few provided the spectrometric identification of the chemical structures of the nonstoichiometric reaction products. In our previous article, ${ }^{8}$ the results of the study on the $\mathrm{PC}-$ epoxy blends cured by a tertiary amine using great excess of oxirane groups 
Table I. Codes, Compositions, and $T_{g} \mathrm{~s}$ of the PC-Epoxy Blends

\begin{tabular}{lclc}
\hline Code & $\begin{array}{c}\text { PC/Epoxy } \\
\text { Weight Ratio }\end{array}$ & $\begin{array}{c}\text { PC/Epoxy } \\
\text { Mole Ratio }\end{array}$ & $\begin{array}{c}T_{\boldsymbol{g}} \\
\left({ }^{\circ} \mathrm{C}\right)\end{array}$ \\
\hline A1 & $254 / 204$ & $100 / 120$ & 147 \\
A2 & $254 / 272$ & $100 / 160$ & 149 \\
A3 & $254 / 340$ & $100 / 200$ & 153 \\
A4 & $254 / 408$ & $100 / 240$ & 140 \\
A5 & $254 / 476$ & $100 / 280$ & 118 \\
& & & \\
B1 & $254 / 102$ & $100 / 60$ & 143 \\
B3 & $254 / 68$ & $100 / 40$ & 136 \\
B4 & $254 / 34$ & $100 / 20$ & 133 \\
B5 & $254 / 17$ & $100 / 10$ & 131 \\
PC & $254 / 6.8$ & $100 / 4$ & 138 \\
\hline
\end{tabular}

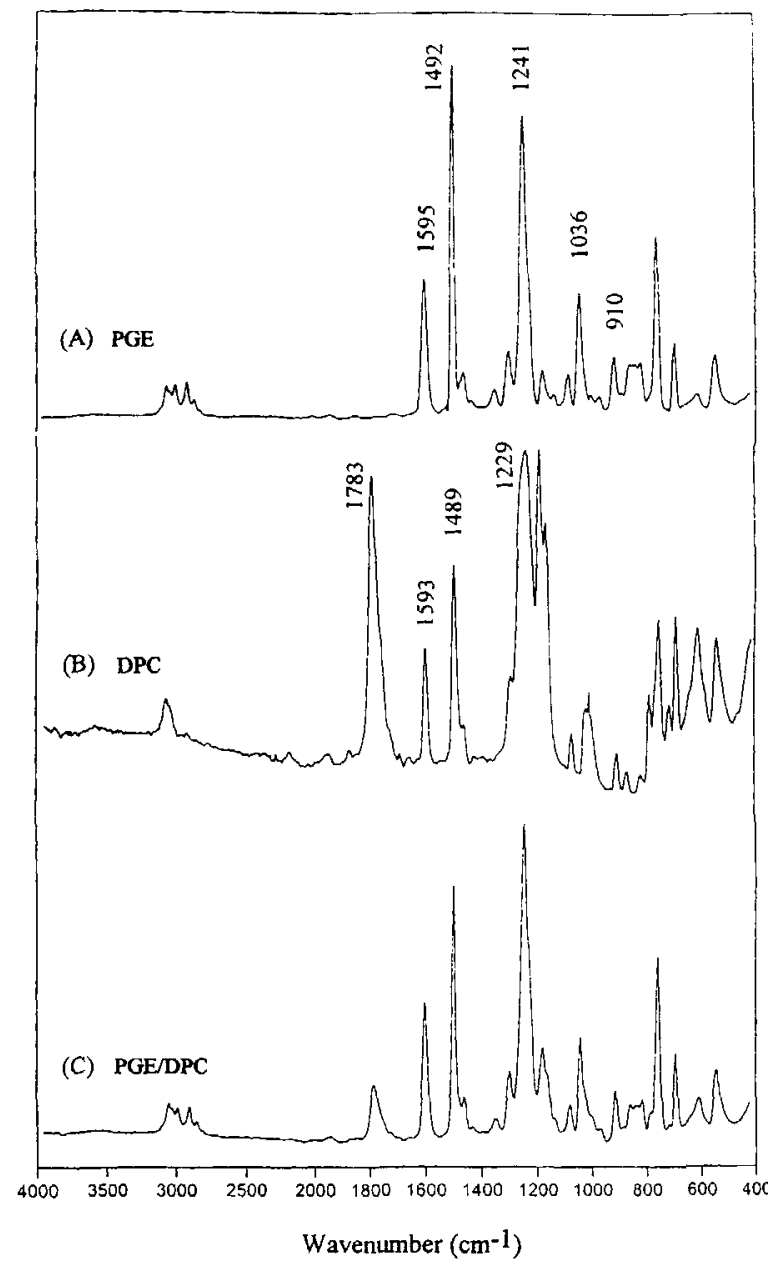

Figure 1. Infrared spectra of (A) PGE, (B) DPC, (C) PGE-DPC mixture with weight ratio of PGE/DPC of 1200 $: 214(w / w)$.

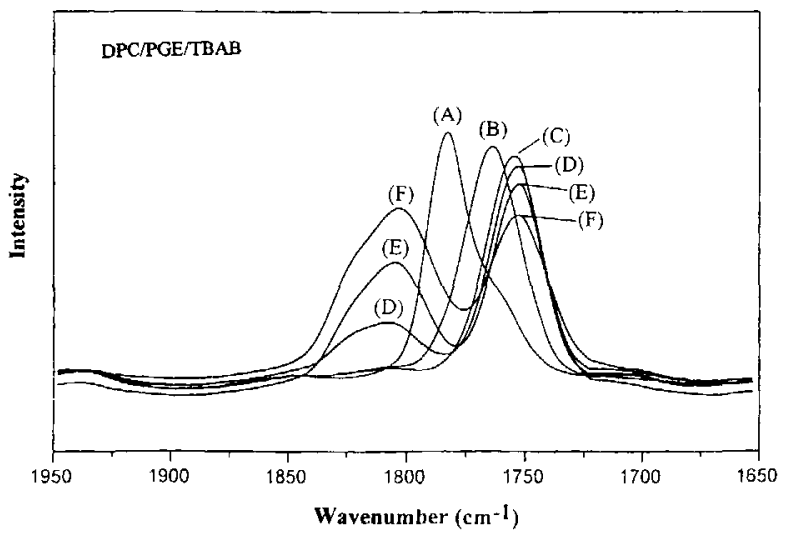

Figure 2. Infrared spectra of DPC-PGE-TBAB mixture with a weight ratio of $214: 1200: 2.4(\mathrm{w} / \mathrm{w})$ recorded in the carbonyl stretching region at $80^{\circ} \mathrm{C}$ : (A) initial; (B) $60 \mathrm{~min}$; (C) $120 \mathrm{~min}$; (D) $120 \mathrm{~min}$ at $80^{\circ} \mathrm{C}$ and $120 \mathrm{~min}$ at $100^{\circ} \mathrm{C}$; (E) $120 \mathrm{~min}$ at $80^{\circ} \mathrm{C}, 120 \mathrm{~min}$ at $100^{\circ} \mathrm{C}$, and 120 min at $120^{\circ} \mathrm{C}$; and $(\mathrm{F}) 120 \mathrm{~min}$ at $80^{\circ} \mathrm{C}, 120 \mathrm{~min}$ at $100^{\circ} \mathrm{C}$, $120 \mathrm{~min}$ at $120^{\circ} \mathrm{C}$, and $120 \mathrm{~min}$ at $150^{\circ} \mathrm{C}$.

relative to the carbonate group were reported. Transesterification reactions of the original diaryl carbonate to form the aromatic/aliphatic and/or the aliphatic/aliphatic carbonates were verified by infrared spectroscopy, and the formation of a cyclic carbonate structure was also detected. The mechanism for the cyclic carbonate formation is assumed to proceed through a zwitterion and a nucleophilic species that attacks the aromatic/ aliphatic or aliphatic/aliphatic carbonate group.
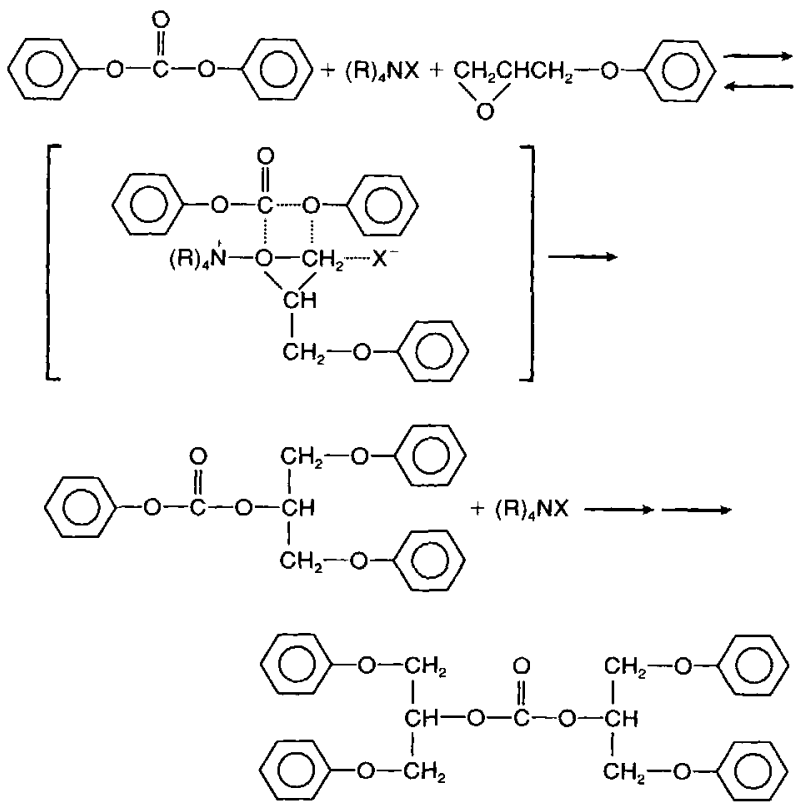

Scheme 1. 


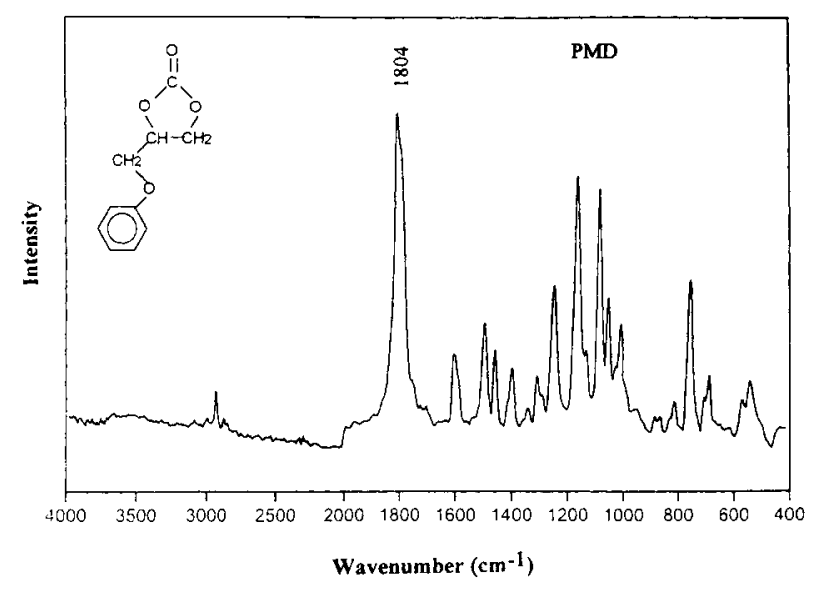

Figure 3. Infrared spectrum of the end product separated from the DPC-PGE-TBAB mixture with a weight ratio of $214 / 1200 / 2.4$.

In this study, the reaction of a nonstoichiometric system of epoxide and carbonate catalyzed by a quarternary ammonium salt is investigated. The infrared spectroscopic results revealed that an unusual structure is produced in the system when the epoxide is in excess. This unknown structure has been identified and the reaction mechanism for the formation of that unknown structure has been proposed. The relationship between the structure and thermal properties of the resulting copolymer will be discussed.

\section{EXPERIMENTAL}

\section{Materials}

The epoxy prepolymer used in this study was DER 332 which is a low molecular weight liquid diglycidyl ether of bisphenol A (DGEBA) with a epoxide equivalent weight of 174 . The polycarbonate used in this study was Calibre 301-15 which is based on bisphenol A, with a melt index of 15 . Both PC and epoxy were purchased from the Dow Chemical Company. The quarternary ammonium salt, tetrabutylammonium bromide (TBAB), was purchased from the Aldrich Chemical Company as a catalyst. The solvent used to dissolve the polycarbonate is dichloromethane which was purchased also from the Aldrich Chemical Company. Silica Gel 60 used in column chromatography was supplied by the Merck Company. The chemicals used in the model reaction study, phenyl glycidyl ether (PGE), diphenyl carbonate (DPC) and diethyl carbonate (DEC), were purchased from the Aldrich Chemical Company. The chemical struc- tures of DER 332, PC, TBAB, PGE, DPC, and DEC are illustrated below:

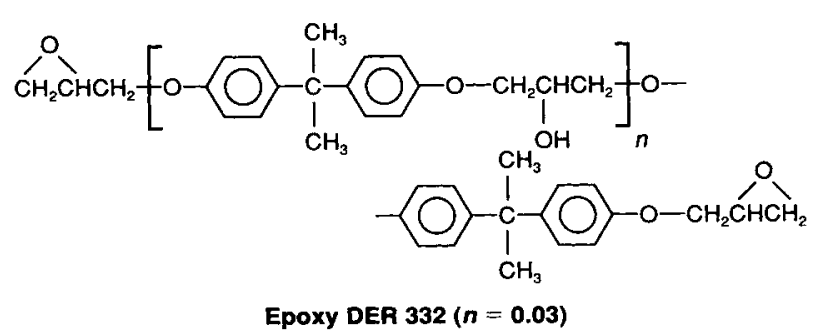<smiles>CC(C)(c1ccccc1)c1ccc(OC(=O)OCC2CC2)cc1</smiles><smiles>CCOCCOc1ccccc1</smiles>

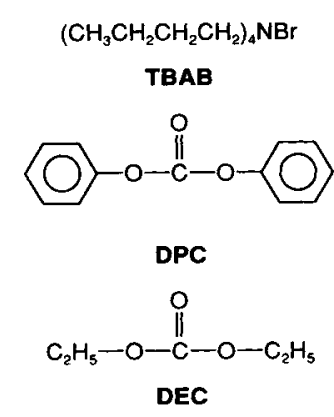

\section{Procedures and Instrumentation}

The experimental procedure for the model reaction was conducted by dissolving DPC and TBAB into $P G E$ at $100^{\circ} \mathrm{C}$. One drop of this mixture was used to prepare a thin film between two sodium chloride plates and then mounted on a sample holder located at the IR instrument. Infrared spectra were obtained on a Perkin-Elmer 842 Infrared Spectrometer with a resolution of $2.4 \mathrm{~cm}^{-1}$ in the transmission mode. IR spectra at elevated temperatures were obtained using a heated cell mounted inside the sample chamber. The resultant products obtained from the model reaction were separated by a silica gel column

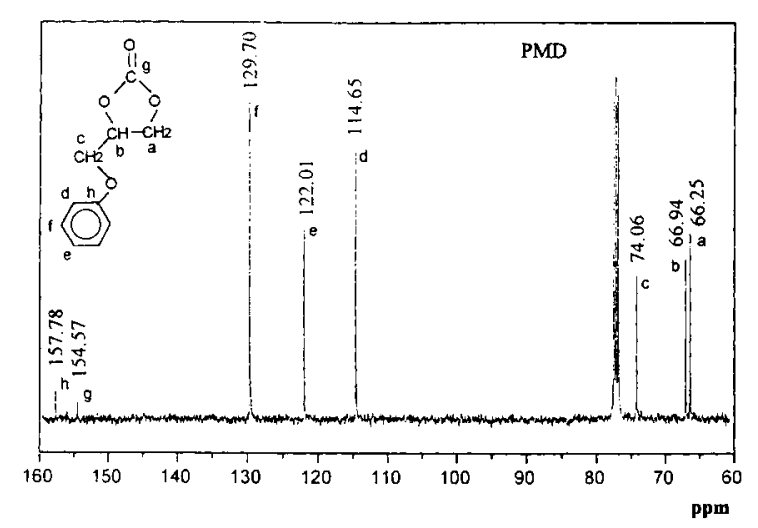

Figure 4. ${ }^{13} \mathrm{C}-\mathrm{NMR}$ spectrum of the end product separated from DPC-PGE-TBAB mixture with a weight ratio of $214 / 1200 / 2.4$. 


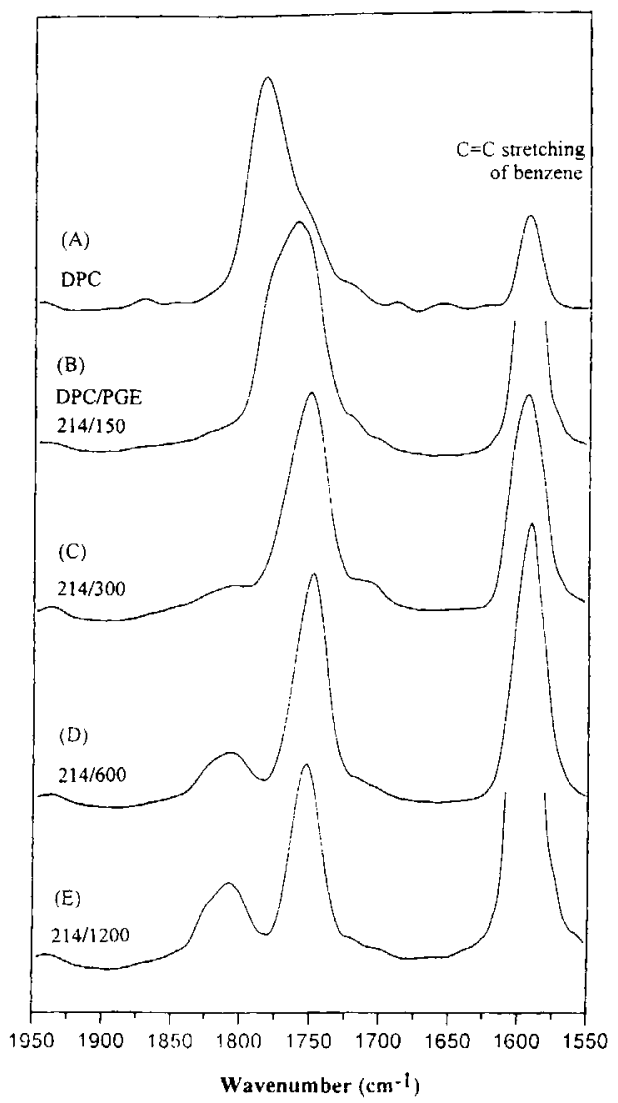

Figure 5. Infrared spectra of (A) DPC, and the end product of DPC-PGE mixture with weight ratio of (B) 214/150, (C) 214/300, (D) 214/600, and (E) 214/1200.

chromatography using dichloromethane as the eluent. The structure identification of the unknown compound obtained from column chromatography was determined by high-resolution ${ }^{13} \mathrm{C}$ nuclear magnetic resonance $\left({ }^{13} \mathrm{C}\right.$-NMR) spectrometry. The ${ }^{13} \mathrm{C}$ NMR spectra were measured with a Bruker $400 \mathrm{FT}$ NMR spectrometer with a magnetic field strength of 9.4 Tesla (e.g., ${ }^{13} \mathrm{C}=100.6 \mathrm{MHz}$ ). Samples were diluted with deuterated chloroform $\left(\mathrm{CDCl}_{3}\right)$. The experimental procedure of $\mathrm{PC}$-epoxy blends was to dissolve $\mathrm{PC}$ into dichloromethane at room temperature to prepare a $15 \mathrm{wt} \%$ solution and to dissolve 2 phr TBAB into the epoxy prepolymer at $100^{\circ} \mathrm{C}$. When the prepolymer was cooled to near room temperature, the $\mathrm{PC}$ solution was added and mixed. The resulting clear solution was then heated at $120^{\circ} \mathrm{C}$ for $1 \mathrm{~h}, 160^{\circ} \mathrm{C}$ for $2 \mathrm{~h}$, and $200^{\circ} \mathrm{C}$ for an additional $2 \mathrm{~h}$. The sample was prepared as a $\mathrm{KBr}$ pellet to detect the variation in the carbonyl group by an infrared spectrometer. The glass transition temperatures of the composites were determined using a Du Pont Differential Scanning Calorimeter (DSC 10) with a heating rate of $10^{\circ} \mathrm{C} / \mathrm{min}$. The compositions of the blends, and their codes are listed in Table I.

\section{RESULTS AND DISCUSSION}

\section{The Model Reaction of Oxirane and Carbonate}

To study the reaction of oxiranes with carbonate groups, PGE and DPC were selected for the model reaction study. Spectrum (A) of Figure 1 shows the IR spectrum of PGE which can be identified from the main absorption peaks as follows: (1) $1595 \mathrm{~cm}^{-1}$, $\mathrm{C}=\mathrm{C}$ (benzene) ring stretch; (2) $1492 \mathrm{~cm}^{-1}, \mathrm{C}=\mathrm{C}$ (benzene) ring stretch; (3) $1241 \mathrm{~cm}^{-1}, \mathrm{C}-\mathrm{O}-\mathrm{C}$ (ether) asymmetrical stretch, (4) $1036 \mathrm{~cm}^{-1}$, $\mathrm{C}-\mathrm{O}-\mathrm{C}$ (ether) symmetrical stretch; (5) 910 $\mathrm{cm}^{-1}, \mathrm{C}-\mathrm{O}-\mathrm{C}$ (oxirane) asymmetrical stretch.

Spectrum (B) of Figure 1 shows the spectrum of DPC which can be identified from the main absorption peaks as follows: (1) $1783 \mathrm{~cm}^{-1}, \mathrm{C}=\mathrm{O}$ (carbonate) stretch; (2) $1593 \mathrm{~cm}^{-1}, \mathrm{C}=\mathrm{C}$ (benzene) ring stretch; (3) $1489 \mathrm{~cm}^{-1}, \mathrm{C}=\mathrm{C}$ (benzene) ring stretch; (4) $1229 \mathrm{~cm}^{-1}: \mathrm{O}-\mathrm{C}-\mathrm{O}$ (carbonate) asymmetrical stretch.

Spectrum (C) of Figure 1 presents the spectrum of a DPC-PGE mixture with a weight ratio of DPC/ $\mathrm{PGE} / \mathrm{TBAB}$ of $214 / 1200 / 2.4$ (mole ratio of DPC/ $\mathrm{PGE}$ is $1 / 8$ ). Comparing spectrum (C) with spectra (A) and (B) of Figure 1 comfirms that no reaction occurs between DPC and PGE during the dissolving procedure. Figure 2 shows the spectra in the carbonyl stretching region of the above DPC-PGE mixture that has been catalyzed by TBAB at $80^{\circ} \mathrm{C}$. Curves (B) and (C) show that the carbonyl absorption band of DPC broadens and shifts to lower frequency. The shift of IR of the carbonyl stretching absorption can be explained as the result of the transesterification reaction. The transesterification reaction proceeds through the formation of an intermediate composed by epoxide, carbonate, and quarternary ammonium salt. The mechanism of transesterification reaction is shown in Scheme $1 .^{2}$

The transesterification reaction converts the original carbonate group of DPC, between two aromatic nuclei $\mathrm{Ar}-\mathrm{O}-\mathrm{CO}-\mathrm{O}-\mathrm{Ar}$, to either one aromatic and one alkyl groups $(\mathrm{Ar}-\mathrm{O}-\mathrm{CO}-\mathrm{O}-\mathrm{R})$, or to two alkyl groups $(\mathrm{R}-\mathrm{O}-\mathrm{CO}-\mathrm{O}-\mathrm{R})$. The absorption frequencies of the aromatic/aromatic carbonate ( $\mathrm{Ar}-\mathrm{O}-\mathrm{CO}-\mathrm{O}-\mathrm{Ar}$ ), aromatic/aliphatic carbonate $(\mathrm{Ar}-\mathrm{O}-\mathrm{CO}-\mathrm{O}-\mathrm{R})$, and aliphatic/ aliphatic carbonate $(\mathrm{R}-\mathrm{O}-\mathrm{CO}-\mathrm{O}-\mathrm{R})$ are at 1776,1762 , and $1746 \mathrm{~cm}^{-1}$, respectively. ${ }^{9}$ The fraction of the original carbonate $(\mathrm{Ar}-\mathrm{O}-\mathrm{CO}-\mathrm{O}-\mathrm{Ar}$ ) is 


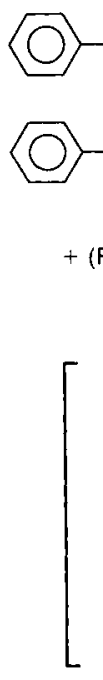<smiles>CCC(CC)OC(=O)Oc1ccccc1</smiles>

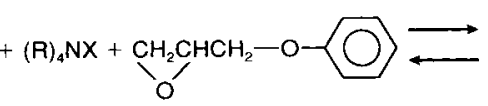<smiles>[X]C1OC(COc2ccccc2)C1OC(=O)OC(COc1ccccc1)COc1ccccc1</smiles>

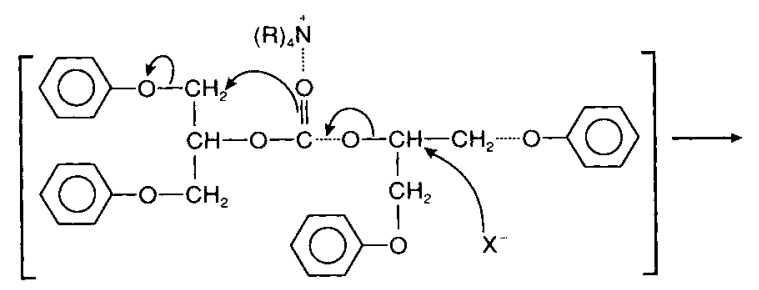<smiles>O=C1OCC(COc2ccccc2)O1</smiles><smiles>O=C(OCc1ccccc1)OC1COc2ccccc2OCC1COc1ccccc1</smiles>

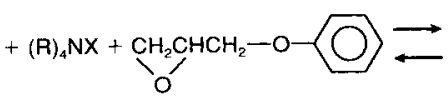<smiles>[X]C(COc1ccccc1)CC(COc1ccccc1)OC(=O)OC(COc1ccccc1)COc1ccccc1</smiles>

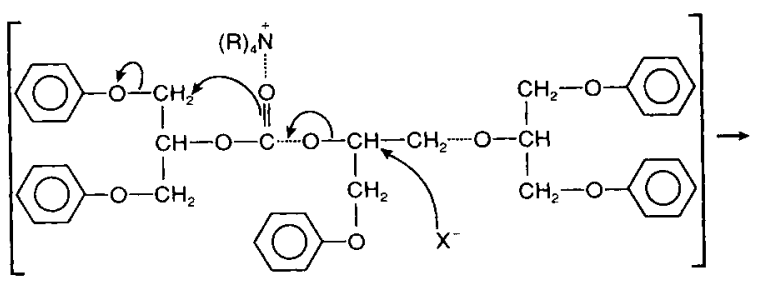<smiles>O=C1OCC(COc2ccccc2)O1</smiles>

Scheme 2.

expected to decrease with the extent of transesterification while the quantity of carbonates from the transesterification increases. This phenomenon is expected to cause the absorption band of carbonyl stretching shifting to lower frequencies. Curve (D) of Figure 2 clearly shows the absorption band splitting into two bands at 1746 and $1810 \mathrm{~cm}^{-1}$, respectively. Curves (E) and (F) show that the intensity of the carbonyl groups at lower frequency further decreases while the absorption of the unknown structure at higher frequency increases substantially. The resulting products obtained from the model reaction can be separated by a silica gel column chromatography into several fractions. However, only one major fraction among them shows the strong characteristic absorption at 1804 $\mathrm{cm}^{-1}$. The fraction of this unknown component with IR band at $1804 \mathrm{~cm}^{-1}$ was used for further structural identification.

The IR and ${ }^{13} \mathrm{C}-\mathrm{NMR}$ spectra of the unknown component are shown in Figures 3 and 4, respec- tively. The IR spectrum (Fig. 3) shows that the $\mathrm{C}=\mathrm{O}$ absorption at $1804 \mathrm{~cm}^{-1}$, a benzene ring $\mathrm{ab}$ sorption between 1600 and $1400 \mathrm{~cm}^{-1}$, some $\mathrm{C}-\mathrm{O}$ absorptions in the region from 1300 to $1000 \mathrm{~cm}^{-1}$, and a monosubstituted aromatic ring pattern at 757 and $707 \mathrm{~cm}^{-1} \cdot{ }^{10}$ The ${ }^{13} \mathrm{C}-\mathrm{NMR}$ spectrum (Fig. 4) of the downfield region shows the chemical shifts at $\delta 114.65, \delta 122.04, \delta 129.70$, and $\delta 157.78$ corresponding to the six carbon atoms of the substituted benzene. The chemical shift at $\delta 154.57$ is attributed to the carbonate group. The chemical shift of the two $\mathrm{CH}_{2}$ groups is at $\delta 66.25$ and $\delta 66.94$ and the $\mathrm{CH}$ group is at $874.06 .{ }^{11}$ Comparing Figure 3 and Figure 4 with the previously reported spectra of 4-phenoxymethyl1,3-dioxolane-2-one (PMD), ${ }^{8}$ the finished product of this model reaction is also PMD. In other words, the model reaction between PGE and DPC with a weight ratio of PGE/DPC of $1200 / 214$ can yield the PMD when the system is catalyzed by either BDMA (tertiary amine) or TBAB (quarternary ammonium 


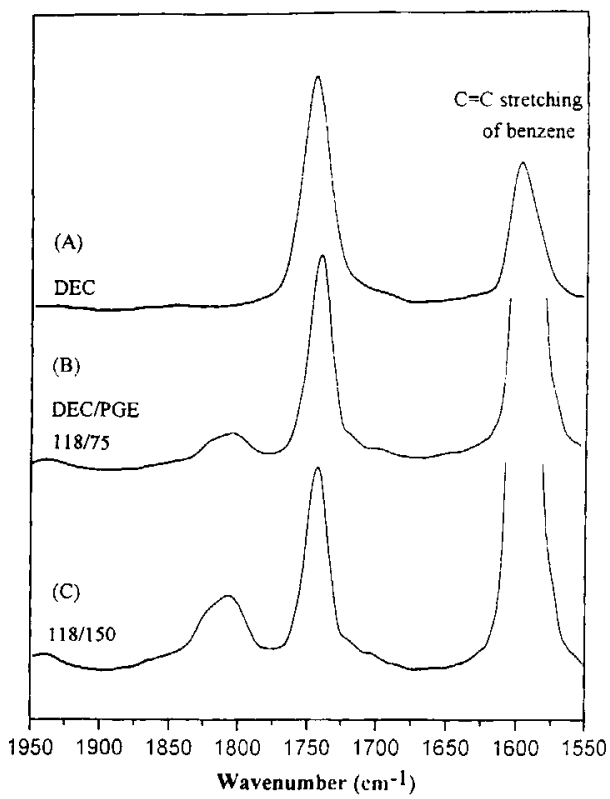

Figure 6. Infrared spectra of (A) DEC, and the end product of DEC-PGE mixture with weight ratio of $(B)$ $118 / 75$ and $(C)$ 118/150.

salt). This phenomenon is somewhat unexpected because PMD is the product of PGE transesterification and cyclization with DPC proceeding through a zwitterion that is formed by oxirane and tertiary amine. ${ }^{12}$ In this PGE/DPC/TBAB system, the zwitterion is not expected to be present in this system. Different cyclization mechanisms must be involved in these two catalytic systems.

To understand the mechanism of cyclization in this system, the formulations of the model reaction were varied with different weight ratios of DPC to

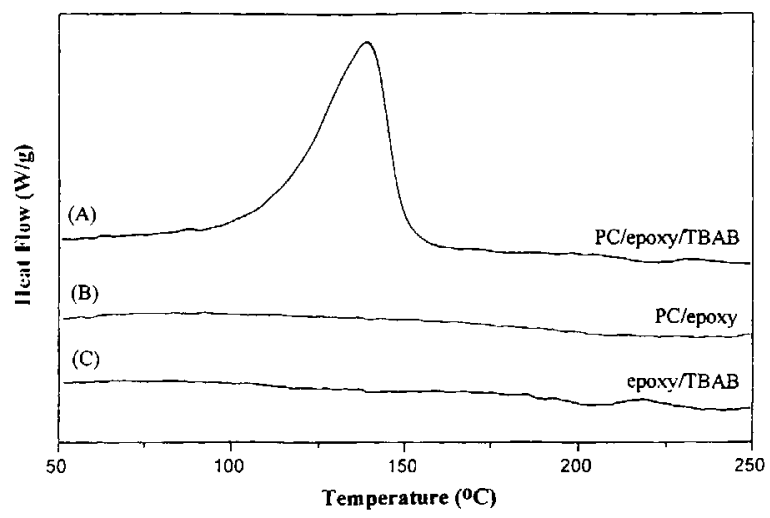

Figure 7. Dynamic DSC runs in the temperature range between $30^{\circ} \mathrm{C}$ and $300^{\circ} \mathrm{C}$ : (A) PC/epoxy/TBAB blend with weight ratio $10 / 100 / 2$, (B) $\mathrm{PC} /$ epoxy blend with weight ratio $10 / 100,(\mathrm{C})$ epoxy/TBAB mixture with weight ratio $100 / 2$.

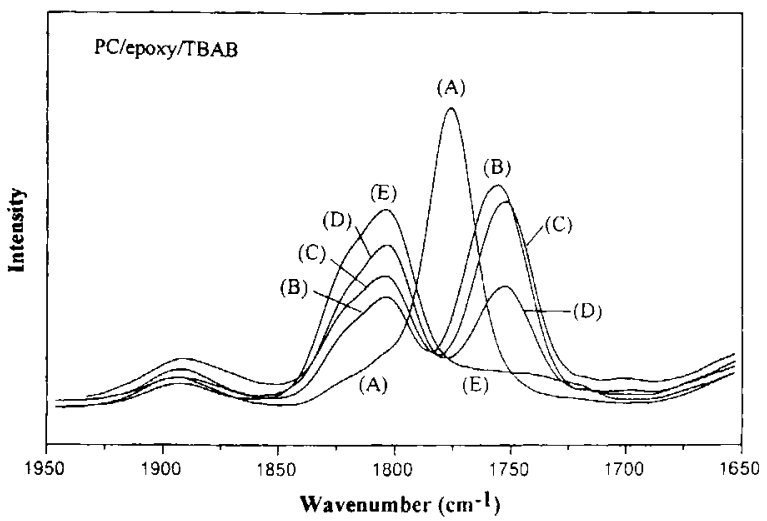

Figure 8. Infrared spectra of PC-epoxy blend catalyzed by TBAB with weight ratio of $\mathrm{PC} / \mathrm{epoxy} / \mathrm{TBAB}$ of $10 /$ $100 / 2$, recorded in the carbonyl stretching region at $80^{\circ} \mathrm{C}$ : (A) initial; (B) $60 \mathrm{~min}$; (C) $120 \mathrm{~min}$ at $80^{\circ} \mathrm{C}$ and $60 \mathrm{~min}$ at $100^{\circ} \mathrm{C}$; (D) $120 \mathrm{~min}$ at $80^{\circ} \mathrm{C}, 120 \mathrm{~min}$ at $100^{\circ} \mathrm{C}$, and $120 \mathrm{~min}$ at $120^{\circ} \mathrm{C}$; and $(\mathrm{E}) 120 \mathrm{~min}$ at $80^{\circ} \mathrm{C}, 120 \mathrm{~min}$ at $100^{\circ} \mathrm{C}, 120 \mathrm{~min}$ at $120^{\circ} \mathrm{C}$, and $120 \mathrm{~min}$ at $150^{\circ} \mathrm{C}$.

PGE. Two parts TBAB catalyst to one hundred parts of PGE were added to this system. Curve (A) of Figure 5 shows the IR band of the unreacted DPC in the carbonyl region. Curves (B)-(E) of Figure 5 show that the IR spectra of the end products from reaction mixtures with weight ratios of DPC/PGE of $214 / 150,214 / 300,214 / 600$, and $214 / 1200$ (i.e. mole ratios are 1 to 1,1 to 2,1 to 4 and 1 to 8 ), respectively. Curve (B) of Figure 5 is the system with excess DPC and with a DPC/PGE weight ratio of $214 / 150$. Since the carbonate group is excess, the oxirane can only transform a fraction of the original aromatic/aromatic carbonate group to the aromatic/ aliphatic carbonate. Curve (C) presents the stoichiometric system of the DPC/PGE mixture with a

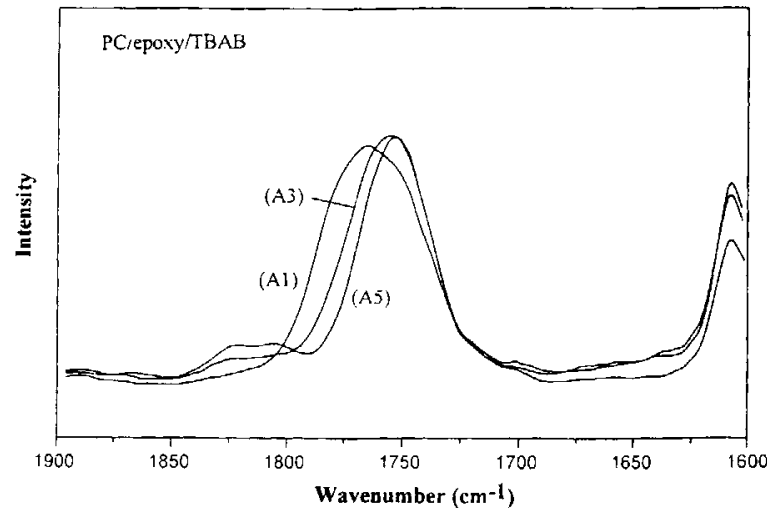

Figure 9. Infrared spectra of the products from PC/ epoxy mixtures catalyzed by 2 phr TBAB with a weight ratio of 254/204 (curve A1), 254/340 (curve A3) and 254/ 476 (curve A5). 


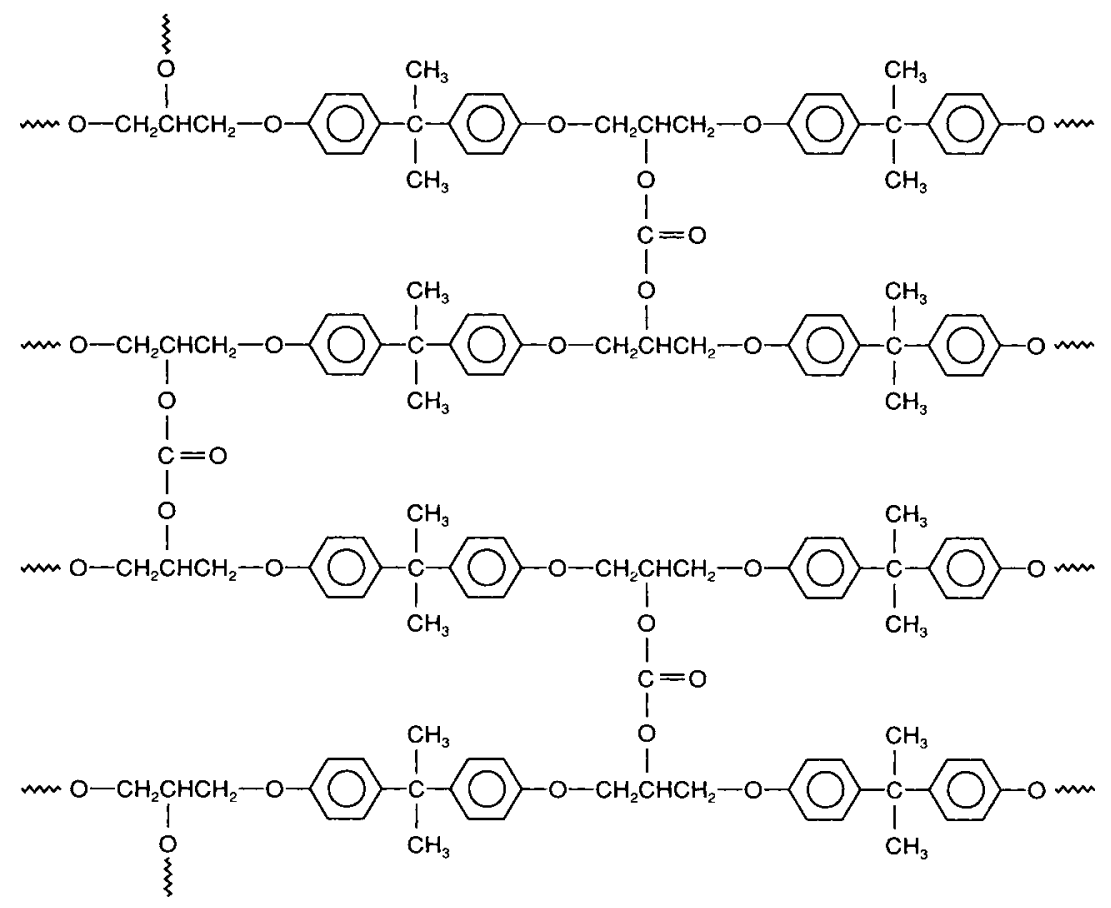

Scheme 3.

weight ratio of $214 / 300$. From this IR spectra, the aromatic/aromatic carbonate mainly interchanges to the aliphatic/aliphatic carbonate. Additionally, the IR absorption of PMD can be detected in this system. Curves (D) and (E) illustrate the IR spectra of the mixtures with PGE in excess where the weight ratios of DPC/PGE are 214/600 and 214/1200, respectively. These two IR spectra with non-stoichiometric PGE rich systems show that the absorption of aliphatic/aliphatic carbonate is gradually reduced in response to the increase of the band of PMD. This phenomenon clearly indicates that the formation of cyclic carbonate (PMD) is closely related to presence of both oxirane and aliphatic/aliphatic carbonate. Thus, the following mechanism is proposed to explain the formation of PMD through the intermediate of transesterification reaction shown in Scheme 2.

Another approach to verify this proposed mechanism is utilizing the aliphatic/aliphatic carbonate (diethylcarbonate, DEC) to proceed the model reaction. Curve (A) of Figure 6 shows the band of DEC in the carbonyl region. As mentioned previously, the absorption band of aliphatic/aliphatic carbonate locates at $1743 \mathrm{~cm}^{-1}$. Curves (B) and (C) of Figure 6 show the IR spectra of the end products from DEC/ PGE mixtures with reactant weight ratios of 118/ 75 and $118 / 150$ (mole ratios are 1 to 0.5 and 1 to 1 ), respectively. Curve (B) of Figure 6 shows that even with excess carbonate, the oxirane still can transform portion of the aliphatic/aliphatic carbonate to the cyclic carbonate. This result supports the above proposed mechanism that the formation of cyclic carbonate proceeds through the intermediate of the transesterification reaction.

\section{Structure of the PC-Epoxy Blends}

Figure 7 shows the DSC results of dynamic runs in the temperature range between 30 and $300^{\circ} \mathrm{C}$. Curve (A) shows the reaction of $\mathrm{PC}$-epoxy blend catalyzed by TBAB. The weight ratio of $\mathrm{PC} / \mathrm{epoxy} / \mathrm{TBAB}$ is $10 / 100 / 2$. Curve $(\mathrm{B})$ presents the PC-epoxy blend with a weight ratio of $\mathrm{PC} / \mathrm{epoxy}$ is $10 / 100$. Curve (C) presents the epoxy that mixed with $2 \mathrm{phr}$ TBAB. From these curves, it can be concluded that epoxy does not react with polycarbonate in the absence of quarternary ammonium salt and the presence of the quarternary ammonium salt also does not catalyze the homopolymerization of the epoxy monomer.

Figure 8 presents the IR spectra in carbonyl stretching regions of the reacting $\mathrm{PC}-$-epoxy blend catalyzed by TBAB, the weight ratio of PC/epoxy/ TBAB is $10 / 100 / 2$. Comparing Figure 8 with Figure 2 , one can find that the same transesterification and cyclization reactions occur in the $\mathrm{PC}-$ epoxy blend as in the model reaction. 

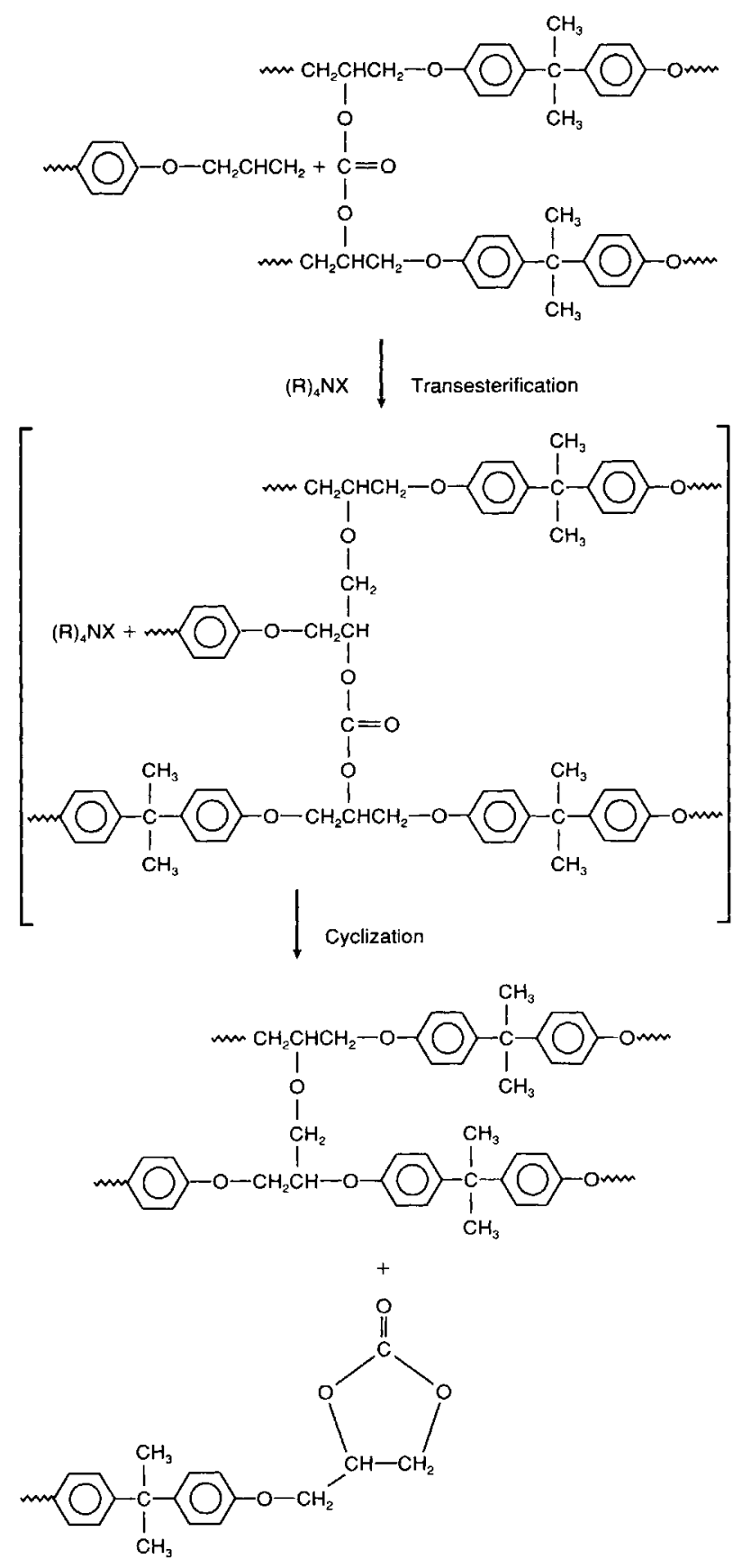

Scheme 4.

Curves (A1), (A3), and (A5) of Figure 9 show that the IR spectra of the products from the mixtures of PC/epoxy catalyzed by 2 phr TBAB with weight ratios of $254 / 204,254 / 340$, and $254 / 476$ (mole ratio of carbonate to oxirane is $50 / 60,50 / 100$, and $50 /$ 140). Curve (A3) presents the stoichiometric system which two oxirane groups react with one carbonate group. The resulted carbonate absorption at $\mathbf{1 7 5 5}$ $\mathrm{cm}^{-1}$ indicates that the original aromatic/aromatic carbonate ( $\mathrm{Ar}-\mathrm{O}-\mathrm{CO}-\mathrm{O}-\mathrm{Ar}$ ) has been converted into the aliphatic/aliphatic carbonate $(\mathrm{R}-\mathrm{O}-\mathrm{CO}-\mathrm{O}-\mathrm{R})$ almost completely. In other words, the epoxy prepolymer is crosslinked by carbonate groups. The structure of the epoxy network crosslinked by the carbonate groups is illustrated in Scheme $3 .^{7}$

Curve (A5) of Figure 9 shows the IR spectrum of the nonstoichiometric system with excess oxirane group. As can be seen from the spectrum, the carbonate absorption peaks appear at $\mathbf{1 7 5 5}$ and 1805 $\mathrm{cm}^{-1}$. The band at lower frequency is the product of the transesterification reaction as mentioned previously and the band of higher frequency comes from the cyclization reaction that has been verified by the model reaction. The crosslink density is expected to decrease with the increase of the cyclization reaction. Based on the proposed mechanism of cyclization, formation of cyclic carbonate will generate chain ends in the network, which are illustrated in Scheme 4.

Curve (A1) of Figure 9 shows the spectrum of nonstoichiometric system with excess carbonate group. The peak of the band at $1765 \mathrm{~cm}^{-1}$ indicates that the oxirane transforms some of the original carbonate $(\mathrm{Ar}-\mathrm{O}-\mathrm{CO}-\mathrm{O}-\mathrm{Ar})$ to aromatic/aliphatic carbonate $(\mathrm{Ar}-\mathrm{O}-\mathrm{CO}-\mathrm{O}-\mathrm{R})$ and aliphatic/aliphatic carbonate $(\mathrm{R}-\mathrm{O}-\mathrm{CO}-\mathrm{O}-\mathrm{R})$. The aliphatic/aliphatic carbonate represents the crosslinking point of the network. The aromatic/aliphatic carbonate represents the point of carbonate insertion by the oxirane. The aromatic/aromatic carbonate reveals that the original PC segments remain in the system. These segments linked with epoxy prepolymer proceed through the aromatic/aliphatic carbonate. The structure of the PC rich nonstoichiometric system is proposed as shown in Scheme 5.

The glass transition temperatures of the blending systems with various compositions measured by differential scanning calorimeter (DSC) are summarized in Table I. Table I shows that $T_{g}$ of the blended system increases when the ratio of the components carbonate/oxirane is increased and reaches a maximum with the stoichiometric ratio (as shown in the composition of A3 in Table I), and then decreases. The stoichiometric ratio of carbonate/oxirane will result in the highest crosslink density, and therefore, possesses the highest $T_{g}$. The $T_{g}$ s of nonstoichiometric systems are always lower than those of the stoichiometric system. It is worthy to mention here that decrease of the $T_{g}$ from the epoxy-rich systems is much more drastic than that of PC-rich systems. This phenomenon can be interpreted as a result that the cyclization reaction occurred, in the epoxy-rich 

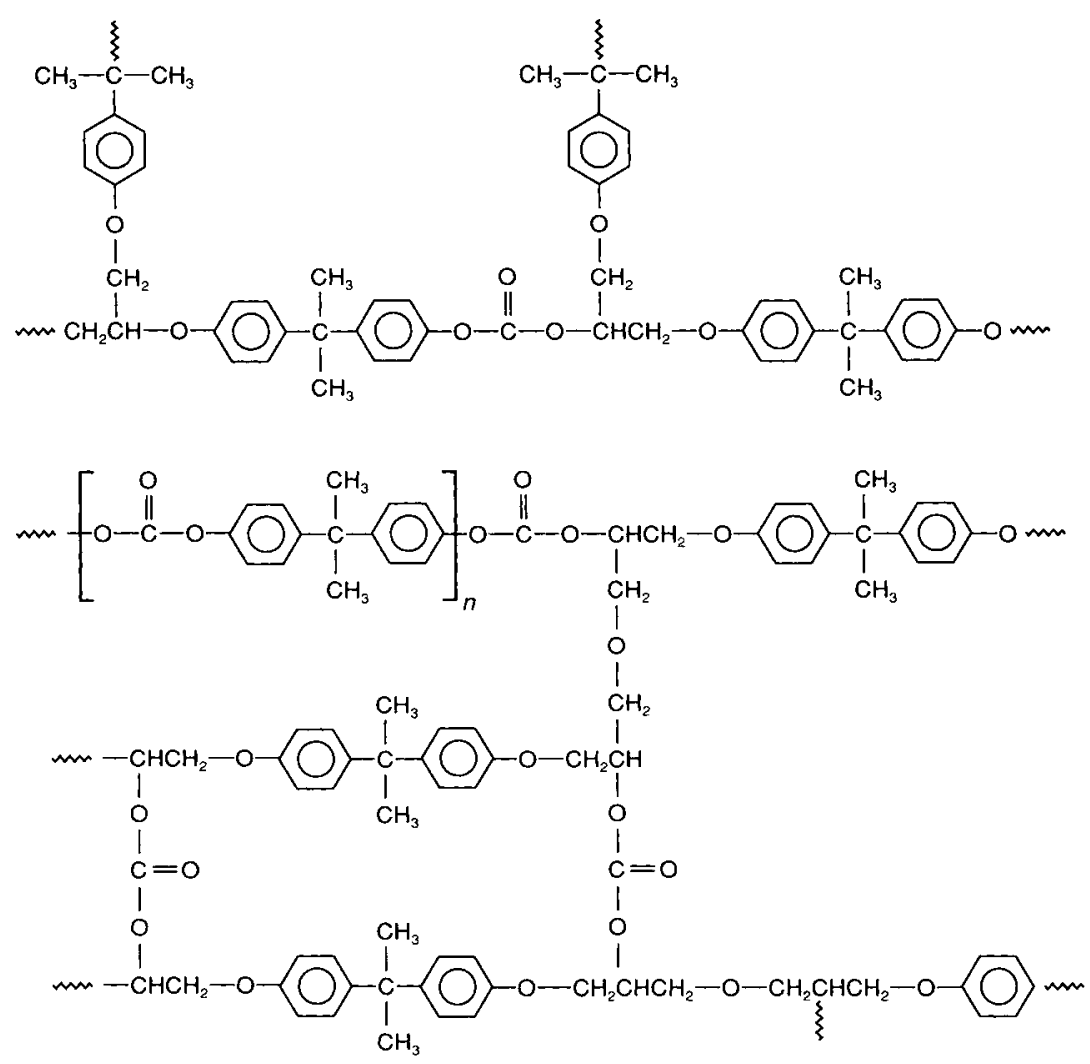

Scheme 5.

systems, more chain ends in the network are created and this decreases the crosslink density. Group B of Table I lists the $T_{g} \mathrm{~s}$ of the systems with excess carbonate group in the blends. The chemical structure of these blending systems can be considered as PC being crosslinked or branched by epoxy resin. However, essentially all of the $T_{g} \mathrm{~s}$ of these blended systems observed are lower than the virgin PC. A reasonable explanation was previously proposed by Nielsen ${ }^{13}$ by considering the influence of crosslinking on $T_{g}$ : (1) the crosslinking effect, and (2) a copolymer effect. Indeed, the crosslinking of the chain of a polymer can cause restriction on the molecular motions, however, a copolymer effect should also be taken into account. A crosslinked unit usually is not structurally the same as the rest of the polymer. ${ }^{14}$ For example, the $T_{g}$ of the cured epoxy resin (DER 332) catalyzed by benzyl dimethyl amine (BDMA) is only $117^{\circ} \mathrm{C} .{ }^{15}$ From the viewpoint of the copolymer effect, the transesterification reaction which introduces the epoxy moieties into PC should decrease the $T_{g}$ of the resultant PC-epoxy blend. The copolymer effect is probably responsible for the observed lower $T_{g}$ due to the chemical composition change by increasing the degree of crosslinkage.

\section{CONCLUSIONS}

The PC-epoxy blends catalyzed by quarternary ammonium salt undergoing transesterification and cyclization reactions were verified by the model reaction. A mechanism has been proposed to explain the formation of the cyclic carbonate structure which proceeds through a transition state of transesterification attacked by the anion of quarternary ammonium salt. With the stoichiometric composition of the PC-epoxy blend which may be cured by transesterification reaction, a network of crosslinked chain will be formed with carbonate groups. The $T_{g}$ of end product is increased and reaches a maximum when the ratio is at stoichiometric value. However, $T_{g}$ decreases drastically in the nonstoichiometric epoxy-rich system. This phenomenon can be explained by chain scissions of the network due to the cyclization reaction; consequently, more chain ends are formed in the network. In the PC-rich system, the epoxy moiety is inserted into PC by the transesterification reaction, and results in crosslinked or branched PC structure. Due to the copolymer effect of PC inserted by epoxy, the $T_{g}$ s of blends are lower than those of the virgin PC. 
This research was financially supported by the National Science Council, Taiwan, Republic of China, under the Contract no. NSC 84-2622-E-007-001. The authors thank Chiu-Ming Chen for helpful discussion and Epolab Chemical Co. for the donation of materials.

\section{REFERENCES AND NOTES}

1. T. Nishikubo, T. Shimokawa, T. Hirano, and A. Shiina, J. Polym. Sci. Part A: Polym. Chem., 27, 2519 (1989).

2. 'T. Nishikubo, T. Iizawa, and S. Saita, J. Polym. Sci. Part A: Polym. Chem., 24, 1685 (1986).

3. T. Nishikubo and K. Tanaka, J. Appl. Polym. Sci., 33(8), 2821 (1987).

4. T. Nishikubo, S. Saita, and T. Fujii, J. Polym. Sci. Part A: Polym. Chem., 25, 1339 (1987).

5. T. Nishikubo, A. Kameyama, C. Maejima, and Y. Yamamoto, Macromolecules, 27, 7240 (1994).

6. L. I. Komarova, S. N. Salazkin, I. A. Bulgakova, M. I. Malaniya, S. V. Vinogradova, and V. V. Korshak, J. Polym. Sci. Polym. Chem. Ed., 16, 1643 (1978).
7. Y. Yu and J. P. Bell, J. Polym. Sci. Part A: Polym. Chem., 26, 247 (1988).

8. M. S. Li, C. C. M. Ma, and F. C. Chang, et al., Macromolecules, 29 (2), 499 (1995).

9. X. Yang, P. C. Painter, and M. M. Coleman, Macromolecules, 25, 4996 (1992).

10. D. L. Pavia, G. M. Lampman, and G. S. Kriz, Jr., Introduction to Spectroscopy, Saunders College Publishing; Philadelphia, 1979.

11. R. M. Silverstein, G. C. Bassler, and T. C. Morrill, Spectrometric Identification of Organic Compounds, Wiley, Singapore, 1991.

12. M. S. Li, C. C. Ma, and F. C. Chang, et al., Proceedings of the International Chinese Symposium on Polymer Blends, Hsin Chu, Taiwan, July 1995.

13. L. E. Nielsen, Mechanical Properties of Polymers and Composites, Dekker, New York, 1974.

14. T. G. Fox and S. Loshaek, J. Polym. Sci., 15, 371, 391 (1955).

15. M. S. Li, C. C. M. Ma, and F. C. Chang, et al., Polymer, to appear.

Received December 11, 1995

Accepted April 10, 1996 